\title{
Study of Network Teaching Resources Integration Mode under informal learning
}

Yan Xia ${ }^{1, a}$

${ }^{1}$ Jiangxi Science \&Technology Normal University, Nanchang, Jiangxi, 330000

a email

Keywords: Informal Learning, Network Teaching Resources, Integration Model

\begin{abstract}
Development of the information age, prompting the network received wide popularity among direct penetration into the teaching field of education, and thus spawned a new network teaching. Network instruction requires extensive network of resources to support teaching, thus building a network of teaching resources is very important. In this context, Web2.0 began to rise, informal learning began to be accepted, and become the current direct people to explore a new way of learning focus. However, because informal learning undertaken accumulated knowledge resources does not get recognized by people, for this paper, teaching resources of informal learning under integration, thus briefly discussed for reference.
\end{abstract}

\section{Introduction}

Construction of network teaching resource is an important foundation for modern education based on information technology, the network transition, but also a significant demand for current educational innovation and reform. At present, China's information technology education really into the use and development phase of the network teaching resources which, over the years by the widespread attention, though its resources construction is not ideal, most of the issues in which there are increasingly beginning obvious [1]. For example, lack of resources flows and development, resource development and practical learning of touch, resources are not fully utilized, and so on. Solve such problems, the moment has become the main education who work with the continuous development of the Internet, Web2.0 era is upon us, informal way of learning began to be introduced, and quickly gained wide acceptance and began to think deeply Network Education and meaning of learning.

\section{Inspiration of Informal Learning Network Teaching Resources}

Informal learning compared to formal learning students pay more attention to the learning process, so the learning process is very important, and in the learning process, students learn to think the content is more important. We can say that learning process itself is carried out its process of thinking, so the stronger full dig out their learning process among resources and effectively use such resources into the appropriate network shared among teaching resource library. Past the traditional formal learning it is difficult to achieve this goal, while informal learning can be effectively's up to the task, for example, students can fully integrate multiple social software to learn.

Since the acquisition of knowledge informal learning directly breaking the previous formal study of the status of teaching resources, such as the traditional teaching resources, almost too much dependent on the teachers themselves personal knowledge base, its resources in the process of updating content It is more difficult and not very practical, is significantly lower in terms of its utilization. And informal learning under way for almost all class learners to explore the role of independent learning, mostly derived from the solution of practical problems, thus showing a very strong purpose [2] as a whole. Therefore, such social learning resources mining, can effectively help teaching resources for better construction and application.

Among the Web2.0 era of today, the network environment is very broad, almost every user can be called the director of the network, so this situation directly broke the previous monopoly of information web portal, directly open the content created by users and user behavior can directly 
affect the development of a new era of network content. And informal learning Under this background undertaken, the real creative play a dominant role in their user status. Network users can directly participate in the resources to create jobs among the click, evaluation and links, greatly influenced the development of its content.

\section{Network Teaching Resources Mode Integration under informal learning}

The main source of teaching resources and digital library construction is both resource database, which can directly become an important supplement to traditional library, which is capable of remote teaching them to play a role in safeguarding the basic document information, it is imperative that network teaching them given high priority. At the same time classroom teachers own stock of knowledge is knowledge of the students who study conduction, which directly and student learning to play a direct correlation effect. And students and their teachers in the teaching of which is also directly play a very important role in the interaction, also known as the effect of teaching and learning. So students knowledge of information feedback in teaching resources among resources of practicality amendment played a most direct relationship. Finally, social learning is accompanied by informal learning behaviors people closest to the natural state, it becomes an important complement formal learning more and more important, the inevitable will greatly enrich the amount of current network construction of teaching resources.

Specific elaborate from the following aspects: (1) to rely on network teaching platform, may establish direct personal portal for each learner, because learners are independent of the implementation of informal learning in the personal portal. Learners as a subset of the network teaching resources into the construction of network teaching platform which can encourage each other to achieve their different individual learning and access to resources. This will not only give full consideration to the learners learning individuality itself, but also the full use of the learning community of collective resources, which greatly improved the traditional concept of resource construction, prompting the entire information transmission becomes more dynamic.

Learners and groups can be found in the absence of the premise of purpose, to collaborate in the construction of knowledge, which once carried the unconscious, aimless informal learning, learning their status are usually produced in the state were accidental. When their group and individual learning is purposeful in the context of the occurrence, its information resource demonstrated by targeted will be very obvious, the quality achieved will also enhance [3]. This requires that the individual should first have a purpose in the background binding to retrieve digital libraries and other personal information portal to integrate knowledge resources, but also directly through google search engine to search for information, and other related software by means of information organize and sick, so as to encourage learners and other individuals and groups, and other produce in real time.

The learner's own individual behavior can also be carried out simultaneously and group behavior, the relationship between the two affect each other and complement each other. The entire process can be directly learners to learn through individual exploration activities empirical knowledge and information, and group activities can be coordinated people's statements, to reflect the feedback and other means. On the one hand in the creation of individual independence and freedom of learning space, some of the tacit knowledge within individual accident will thus be released. Knowledge resources of individual learning thus between the groups to share and exchange. Conversely, learners can also be performing at the same time group collaboration, the exchange of tacit knowledge obtained, which will be the learning process of the individual in the future some impact.

To explore the process of learning resource, thereby focus on the integration of content resources that belong to the model, since the model itself makes full use of social software to obtain information, processing, exchange and polymerization many other work. Thereby realizing its entire learning process and organize resources to explore, such as through a search engine can easily get access to knowledge through social software enables real-time communication and communication, and information can be achieved through the RSS link and polymerization. As to how the integration of such resources, specifically binds to two steps, first add the RSS function module in 
online teaching portal, so as to achieve the population and individual resources effectively aggregation and explore. The second is the need to explore the process of informal learning resources are classified and included in the repository for sharing.

Learners need to organize and evaluate learning materials, which is to ensure the quality of teaching resources network key. Since the information resources are often accompanied by a learning process to obtain continue to produce, and how to organize and expand its evaluation of the model is to improve the difficulty lies. Specifically the following aspects need to be: first, the need to view subscription rates and the number of clicks of information, in general, they have the quality and value of the resource is vulnerable to concerns related to the learner. The second is relevant to the needs of teachers throughout the process to be responsible for the quality of supervision, and thus more valuable resources to recommend timely correct some erroneous ideas. Note that in informal learning, teachers play a major oversight role, which is of great significance.

\section{Conclusion}

In summary, today's informal learning belongs to an important extension of the Internet age in which the field of education, but it still has obvious unofficial characteristics, can not completely replace the traditional formal learning. However, it has a very significant research value, for the construction of teaching resources in terms of great significance.

\section{References}

[1] Song Quanhuan. SCORM standards-based network of informal learning Resource Development Model [J]. Continuing Education, 2014, v.28; No.22912:. 44-46.

[2] Wang Yanli, Yang Gaixue, Wang Juan, Yang Ruijiao. informal learning content based on a review of domestic analysis [J]. Journal of Distance Education, 2011, v.29; No.20504: 71-76.

[3] Zhang Lina, Jike. Bilecik Web2.0 environment informal learning research literature review [J]. e-commerce, 2014, No. 17305: 72-73. 